\title{
EDINA Digimap: New Developments in the Internet Mapping and Data Service for the UK Higher Education Community
}

\author{
by BARBARA MORRIS, DAVID MEDYCKYJ-SCOTT \& \\ PETER BURNHILL
}

\section{INTRODUCTION}

Following successful trials in six United Kingdom university map collections, the EDINA Digimap ${ }^{1}$ web-based mapping service was launched on 10 January 2000. Digimap gives access to current Ordnance Survey of Great Britain (OS) maps ranging in scale from $1: 1,250$ to $1: 250,000$ and also to the raw digital map data. This paper looks at the background to the service, the facilities it offers to the UK Higher Education (HE) community, and future plans for incorporating other data, including historic mapping and aerial photography.

\section{BACKGROUND}

In the 1990s, map library users were increasingly wanting access to map information in digital form as well as on paper. The existence of digital map data had begun to affect map library activities, particularly their archiving role, and many map librarians felt ill-prepared to deal with these data. Some of the main barriers related to the cost of acquisition, but also to software, hardware, and operation. There were skill hurdles too to overcome with software, data, hardware, and networks, and the issues of copyright and royalty had yet to be satisfactorily resolved.

\section{WHY THE INTEREST IN OS DigITAL MAP DATA?}

Any subject with a spatial dimension in the UK has a potential interest in OS digital map data. These multi-disciplinary resources have proved their appeal in almost every field of research and teaching in Higher Education, providing 
a geographic framework for integrating other data. In the 1990s, the traditional means of consulting large-scale OS paper maps was under threat, with paper maps only being printed on demand and at a cost beyond the means of most UK map collections. OS Digital Map Data was increasingly being used in a large number of companies but the demand for these data within Higher Education, where potential employees were being trained, was unknown.

\section{The Digimap PRoject}

Digimap began as a project in Edinburgh University Data Library in 1996, funded under the Electronic Libraries (eLib) Programme of the Joint Information Systems Committee (JISC) of the UK Higher Education Funding Councils. The Digimap demonstrator service was tested in six UK university map collections, each chosen because of their different set-up. Table 1 analyses users of the demonstrator by category and subject. There were two main surprises, first that almost fifty per cent of our users were undergraduates, a much higher proportion than recorded for other on-line services offered to Higher Education in the UK and, second, eighty per cent of users were non-geographers. The overall results of the trial were very positive and informed the negotiations between Ordnance Survey and the JISC to establish a national service. The contract to run the service, available on subscription to all UK Higher Education institutions, was awarded to EDINA, based in Edinburgh University Data Library. EDINA is one of three UK national data centres which provide on-line services for the UK tertiary education and research community.

Table 1: Users of the Digimap Demonstrator, 1997-9

\begin{tabular}{|l|c|c|}
\hline Users 1997-9 & $(\%)$ & $(\%)$ \\
\hline Category as of June 1999 $(n=850)$ & & \\
\hline Undergraduate & 49 & \\
\hline Postgraduate & 20 & \\
\hline Staff/research & 31 & \\
\hline
\end{tabular}




\begin{tabular}{|l|c|c|}
\hline Users 1997-9 & $(\%)$ & $(\%)$ \\
\hline Subject as of April 1999 $(n=616)$ & & \\
\hline Economic \& Social Sciences & & 25 \\
\hline Engineering \& Physical Sciences & & 18 \\
\hline Biotechnology \& Biological Sciences & & 16 \\
\hline Natural Environment & & 11 \\
\hline Medical Research & & 5 \\
\hline Arts \& Humanities & & 5 \\
\hline Particle Physics \& Astronomy & & 1 \\
\hline Information Services & & 15 \\
\hline Other & & 4 \\
\hline
\end{tabular}

\section{THE EDINA Digimap NATIONAL SERVICE}

EDINA Digimap is a JISC-funded, web-based mapping service, created and hosted by EDINA, with support and training supplied jointly with MIMAS (another UK national data centre). Access to Ordnance Survey map data is via an easy-to-use, map-based interface, which allows the user to create maps on-screen, print high quality maps, and download map data.

Since the launch of the service on 10 January 2000, Digimap has quickly become a well-established part of the EDINA portfolio. By June 2000 it was supporting some 1,500 users from 43 institutions. Users had viewed 74,000 on-screen maps and produced 4,800 EPS files for high quality printing. Many other users simply printed a draft quality GIF image directly from the browser. Digimap Download has been very intensively used by a subset of specialist users wishing to process the map data in their own software. Around 10,000 tiles of map data have been downloaded in this way by around 150 users. Many users navigate the service using the on-line help and tutorials. EDINA feels that the key to success was in making the data usable.

The institutions subscribing to Digimap span Britain from Aberdeen to Portsmouth, from East Anglia to Glamorgan; and span the ages from Oxford and Glasgow to some of Britain's newest Higher Education institutions. The Digimap service represents a breakthrough in the use of Ordnance Survey data for UK Higher Education, with previously unheard of flexibility in the copyright agreement. 
EDINA Digimap: New Developments in the Internet Mapping and Data Service for the UK Higher Education Community

Table 2: Some uses of OS data by Digimap users

\begin{tabular}{|l|l|}
\hline Subject & Use \\
\hline Archaeology & Location modelling of Bronze Age settlements \\
\hline Architecture & Model making and urban planning \\
\hline Astronomy & Assessing topography for telescope location \\
\hline Biological Science & Vegetation ecology \\
\hline Civil Engineering & Locating hydrogen plant for fuelling buses \\
\hline Computer Science & Research into graphics and visualisation \\
\hline Earth Sciences & Tectonics and landscape evolution \\
\hline Economics & Shopping vitality study \\
\hline Electronics & Teaching position location using mobile radio \\
\hline Geography & Linking weather station and road accident data \\
\hline History & The feeding of Oliver Cromwell's New Model Army \\
\hline Law & Analysis of police recorded crime \\
\hline Mathematics & Modelling rainfall with topographic variables \\
\hline Medicine & Pollution monitoring for Public Health Services \\
\hline Pharmacology & Study of health inequalities \\
\hline Planning & Brown-field site regeneration studies \\
\hline Zoology & Mapping of water vole distributions \\
\hline
\end{tabular}

A simple mapping and downloading service is available to all institutions. An advanced mapping service (Carto) is available only to Site Representatives at present but will be accessible to all users early in 2001 (Figure 1). It is clear that this is only the beginning. Six additional institutions plan to subscribe from the start of the Academic Year 2000-1 with a number of others coming along to our Training Courses to find out more. In institutions that are already signed up, we know that the level of activity will increase as arrangements to register users are refined and more teaching departments make use of the service. 


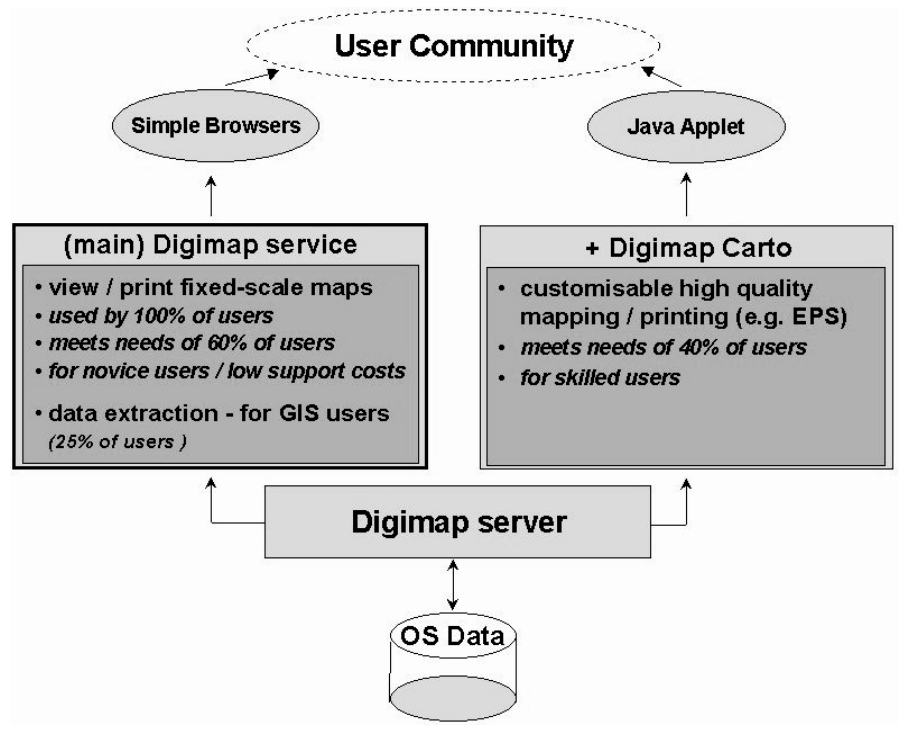

Figure 1: Serving the user community

Data available under the JISC/OS deal includes national cover vector data at 1:250,000 scale (Strategi ${ }^{\odot}$ ), 1:50,000 scale contours and Digital Terrain Model (Land-Form PANORAMA ${ }^{\mathrm{ru}}$ ), 1:50,000 scale transport, administrative boundaries, land use (Meridian $^{\text {t) }}$ ), and the 250,000 names in the1:50,000 Place Names Gazetteer. Thirty per cent of the country is available for users to choose from the large-scale Land-Line.Plus ${ }^{\circledR}$ product. Land-Line.Plus ${ }^{\circledR}$ varies in scale from 1:1,250 in urban areas to 1:10,000 in mountains and moorland. These data are delivered to EDINA as tiles varying in coverage from $500 \mathrm{~m}$ by $500 \mathrm{~m}$ to $5 \mathrm{~km}$ by $5 \mathrm{~km}$, depending on the scale. Strategi ${ }^{\oplus}$, Land-Line ${ }^{\circledR}$, and the Gazetteer are updated annually. Meridian ${ }^{\mathrm{TM}}$ lacks the detail required by users (the 1:50,000 colour raster maps were the preferred choice of users) but is being extended to include water features and woodland. Hopefully this will be available to users next year.

The decision to make only thirty per cent $(69,000$ tiles) of the large-scale mapping of Great Britain available each year was made by the JISC and OS on financial grounds. As a consequence, it was necessary for EDINA to develop a rationing system, which was seen to be fair and workable by the academic community. EDINA designed and implemented a Java application which has been used by site representatives to nominate and confirm tiles to be added to a pool. All users have access to tiles in pool. A year is divided into 
approximately three periods. In the first period, thirty per cent of the available 69,000 tiles are shared equally among subscribing institutions. In the second, the remaining tiles are shared between all subscribing institutions. In the final stage a contingency fund of 3,000 tiles is shared out on a needs basis. One benefit of the process has been that it has proved a good way for Map Librarians to get to know their users. Users have to inform Map Librarians as to which tiles they want added to the pool.

\section{How We have Made the Data Usable}

Feedback during the trial indicated that users liked their maps to look as close to the familiar OS paper products as possible. EDINA has, therefore, invested considerable effort to achieve this sine the data, as delivered from OS, does not make a cartographically attractive and usable map when displayed on the screen or printed. (See additional figures in the web version of this paper.)

\section{SUPPORTING A HETEROGENEOUS USER COMMUNITY}

Evaluation work in the Digimap Project resulted in production of a comprehensive support strategy. OS data are complex and current knowledge amongst many Map Librarians and other user support staff is low. For the national service we have, therefore, offered a significant amount of support on-line including training course/user fora; on-line help and tutorials; teaching resources; case studies, and glossaries. There is also easy assess to the EDINA helpdesk, educational materials, email lists/discussion fora, and links to other resources. Local support from technical and subject experts within institutions is crucial. We are assisting sites in training staff to support the service. From our Digimap Project surveys, we found that Map Librarians were the most valued method of support for users.

\section{LESSONS LEARNT FROM THE TRIAL}

Feedback from the trail suggested that in order to allow universities to pursue their activities, EDINA had to ensure that the service was accessible to all staff, postgraduates, and undergraduates, regardless of the source of their financial support, the version of web browser to which they had access, or whether the computer was located within their institution or at their residence. In order to achieve this, EDINA had to ensure that the right support 
structure was in place, that a suitable delivery mechanism was deployed, that the technology was up to the job, and the necessary resources were in place to keep pace with a fast-moving area.

\section{FUTURE DEVELOPMENTS}

\section{Historic Ordnance Survey Maps}

The EDINA Digimap national service currently provides access only to up-todate Ordnance Survey mapping but many academic users are interested in the ,Changing Landscape'. They need easy access to data with an historical as well as a geographical dimension. Digimap.Plus, the research and development arm of the service, has begun to respond to the demands of social scientists, medical researchers, archaeologists, lawyers, engineers, and others, by developing a web application to deliver Ordnance Survey historical mapping for teaching and research. This will be tested in the six trial sites before becoming part of the national service. Raster images (tiff, 300 dots per inch) of Edinburgh and Newcastle have been acquired from the Landmark Information Group representing maps based on the Cassini Projection of five epochs (1843-93, 1891-1912, 1904-39, 1919-43, and from 1945 onwards). These are available at scales of 1:2,500 and 1:10,560, from the First through to the Fourth Series. As part of the ,Changing Landscape' research, Digimap.Plus will also investigate how to manage different editions of OS digital map data supplied to the national service.

\section{Aerial Photography}

Another source for looking at change is aerial photography. ,Cities Revealed' is modern, full colour, vertical aerial photography covering major GB cities, provided by the Geoinformation Group (in tiff format, at a resolution of 300 dots per inch). The photoscale is 1:7,000-1:18,000. Its $25 \mathrm{~cm}$ resolution means that trees, roads, buildings, development sites, and individual cars, sometimes even their makes, can be recognised (illustrated in the web version of this paper). Staff and students will be able to view, print, and download images for use in a digital format within a GIS, word processing, or mapping tool. A pilot service with photography of Edinburgh, Glasgow, Newcastle, and Reading will start in October 2000 in six UK universities, Aberdeen, Glasgow, Edinburgh, Newcastle, Oxford, and Reading, the same six institutions involved in the original Digimap trial between 1997 and 1999. We would like, 
eventually, to open up the ,Changing Landscape' facility to all EDINA Digimap subscribing institutions and to increase the amount of data available. This new service would complement other EDINA geo-data services, which deliver UK Agricultural and Horticultural Census data, and boundary data (UKBORDERS).

\section{Distributed National Electronic Resource (DNER) Projects}

A number of new nationally funded projects with a geographical dimension, which will enhance EDINA national services, are under way or planned for the near future. These projects have been funded under the JISC DNER Programme. The first is the development of a Geo-data Portal for the UK Higher Education community. Phase 1, which started in August 2000, is a scoping study into the establishment of a z39.50 compliant geo-data browser. This will allow staff and students to discover what geo-data exists within UK Higher and Further Education and the geographic community in general. A second project is Geo-Crosswalk, a feasibility study into the provision of a British and Irish Gazetteer service, starting in October 2000. The third is Digimap New Tools, designed to enhance the DNER for learning and teaching, involving case studies, learning tools, ,virtual placements', and starting in January 2001.

\section{CONCLUSION}

In general, the development by the Data Library of a service on-line access to OS data can be considered a great success. Many more staff and students are using OS data than was previously the case and many innovative projects are underway which previously were not possible because of the prohibitive cost of the data or lack of guaranteed access. In terms of diffusion of innovation, there is anecdotal evidence that it is often students who discover the service first, with lecturers only becoming aware of it when students hand in projects containing maps they produced using Digimap.

Some map librarians have been and remain unhappy about various aspects of the service, for example, that an on-line service means that users by-pass map librarians. The map librarians then have difficulty getting feedback about use of the service. Interestingly, having responded to the request from map librarians to reduce their workload by providing users with access to on-line registration forms, we now get complaints that this has further lowered direct 
contact with users. EDINA encourages map librarians and other local support staff to point users to local facilities and expertise through their institution's web pages.

Another complaint is about the level of support map librarians need to offer users and on their own levels of technical skill in the use of equipment and data. It is perhaps worth noting that the majority of supporting staff within an institution are NOT map librarians or curators, rather they tend to be in either learning resources or computing service roles. It has been pointed out that these individuals may prove more adept at handling digital map data and could remove the need for the map librarian. Indeed, Digimap and similar services may ,fracture the role of the university map library as a supplier of geo-spatial information'. However, some map librarians have seen the introduction of the service as a positive thing and been very proactive in making links with users rather than waiting for users to come to them. They have also seen the service as an opportunity to up-skill themselves; for example, EDINA offers comprehensive courses on the use of OS data in GIS and is actively trying to find a way to fund more general GIS courses for both users and map librarians. It will be interesting to see how things develop vis-àvis the role of the map librarian as Digimap continues to develop, additional data sets are added and other on-line geo-spatial application services begin to become available to higher and further education in the UK.

\section{REFERENCES}

$1<$ http://edina.ac.uk> 